\title{
Circadian Perinatal Photoperiod Has Enduring Effects on Retinal Dopamine and Visual Function
}

\author{
Chad R. Jackson, ${ }^{1}$ Megan Capozzi, ${ }^{1,2}$ Heng Dai, ${ }^{1}$ and Douglas G. McMahon ${ }^{1}$ \\ ${ }^{1}$ Department of Biological Sciences, Vanderbilt University, Nashville, Tennessee 37235 and ${ }^{2}$ Department of Molecular Physiology and Biophysics, \\ Vanderbilt University School of Medicine, Nashville, Tennessee 37235
}

\begin{abstract}
Visual system development depends on neural activity, driven by intrinsic and light-sensitive mechanisms. Here, we examined the effects on retinal function due to exposure to summer- and winter-like circadian light cycles during development and adulthood. Retinal light responses, visual behaviors, dopamine content, retinal morphology, and gene expression were assessed in mice reared in seasonal photoperiods consisting of light/dark cycles of 8:16, 16:8, and 12:12 h, respectively. Mice exposed to short, winter-like, light cycles showed enduring deficits in photopic retinal light responses and visual contrast sensitivity, but only transient changes were observed for scotopic measures. Dopamine levels were significantly lower in short photoperiod mice, and dopaminergic agonist treatment rescued the photopic light response deficits. Tyrosine hydroxylase and Early Growth Response factor-1 mRNA expression were reduced in short photoperiod retinas. Therefore, seasonal light cycles experienced during retinal development and maturation have lasting influence on retinal and visual function, likely through developmental programming of retinal dopamine.
\end{abstract}

Key words: circadian; dopamine; electroretinogram; photoperiod; retina; vision

\section{Introduction}

The structure and function of the visual system is influenced by light input during development. Altered visual or photic input results in enduring changes in the structure and function of central visual centers in the visual cortex and the rhythmic nature of the light-modulated suprachiasmatic nuclei located in the hypothalamus (Hubel and Wiesel, 1962; Ciarleglio et al., 2011). Upstream from these sites, the neural retina transduces environmental light signals to these brain areas; moreover, the retina can also be developmentally programmed by light stimulation. Here, we examined whether circadian light cycles experienced during development can have enduring effects on retinal function in adulthood.

Light-driven neural activity influences the development of retinal circuits, and rearing mice in darkness alters retinal synaptic organization, which leads to permanent alterations in visual function (Melamed et al., 1986; Tian and Copenhagen, 2001). While rearing animals in constant darkness alters retinal and visual function, we have focused on the potential for enduring effects of altered circadian light cycles-short photoperiods with

Received Nov. 20, 2013; revised Feb. 2, 2014; accepted Feb. 24, 2014.

C.R.J., M.C., H.D., and D.G.M. analyzed data; C.R.J., M.C., and D.G.M. wrote the paper.

This work was supported by multiple grants from the National Institutes of Health [R01 EY015815 (D.G.M.), F32 EY022850-01 (C.R.J.); Vanderbilt Vision Research Center, P30EY008126; T32 EY07135-16; and P50 MH096972 (Vanderbilt Conte Pilot Grant)]. We would also like to thank the Vanderbilt Neurochemistry Core (Dr. Raymond Johnson) and the Vanderbilt Vision Research Histology Core (Mariesol Rodriguez) for their technical expertise and effort.

The authors declare no competing financial interests.

Correspondence should be addressed to Douglas G. McMahon, 465 21st Avenue South, Room 8270 MRB3, Department of Biological Sciences, Vanderbilt University, Nashville, TN 37235. E-mail: douglas.g.mcmahon@vanderbilt.edu.

DOI:10.1523/JNEUROSCI.4887-13.2014

Copyright $\odot 2014$ the authors $\quad 0270-6474 / 14 / 344627-07 \$ 15.00 / 0$
$8 \mathrm{~h}$ of light per day that mimic winter light cycles at mid latitudes, and long photoperiods with $16 \mathrm{~h}$ of light per day that mimic summer photoperiods- presented during the perinatal period of mouse development and maturation. Seasonal circadian light cycles experienced during development can imprint the properties of other neural and endocrine systems in mammals, shaping the function of circadian clock neurons in the central circadian clock (Ciarleglio et al., 2011) and the rate of sexual maturation (Goldman, 2003). Moreover, recent results in mice suggest the potential for circadian light reception by melanopsin-expressing retinal ganglion cells in utero, extending the concept of developmental influence of light on the retina (Rao et al., 2013), but without an identified mechanism.

Here, we found that mice reared on a short, winter-like, photoperiod display enduring decreases in retinal light responses and contrast sensitivity. These physiological changes are underlain by decreases in retinal dopamine levels, reduced expression of the transcripts for the principal synthetic enzyme for dopamine synthesis, and an activity-dependent transcription factor. Thus, circadian photoperiods experienced during perinatal development and maturation have long-lasting impact on retinal function.

\section{Materials and Methods}

Animal usage and care. All animal protocols were approved and in accordance with the guidelines established by the Vanderbilt University Animal Care Division, and the National Institutes of Health Guide for the Care and Use of Laboratory Animals. For this investigation, male C57/ BL/6 mice were reared in three different lighting conditions: (1) Long photoperiod (L), mice were exposed to $16 \mathrm{~h}$ of light and $8 \mathrm{~h}$ of dark; (2) Short photoperiod (S), mice were exposed to $8 \mathrm{~h}$ of light and $16 \mathrm{~h}$ of dark; and (3) Equinox photoperiod, mice were exposed to $12 \mathrm{~h}$ of light and $12 \mathrm{~h}$ of dark (Fig. 1). The Equinox group is considered the control group in this study. Mice were reared in their respective lighting environments 
from embryonic day 0 (E0) to postnatal day 40 (P40), and then were either switched to the opposing light cycle or maintained on the original cycle (Fig. 1; Long photoperiod to Short photoperiod [L:S], Short photoperiod to Long photoperiod [S:L], Long photoperiod to Long photoperiod [L:L], Short photoperiod to Short photoperiod [S:S]). Once mice were switched to the new lighting environment, they were allowed to acclimate to the new environment for at least 3 weeks before testing. Unless otherwise noted, mice were tested during the middle of the light phase of their respective light cycles (11:00 A.M.-1:00 P.M. on all light cycles; Fig. 1, denoted by gray arrow). Studies show that retinal development, maturation, and vision in mice become mature at approximately P30 (Tian and Copenhagen, 2001; Prusky et al., 2004); therefore, we chose $\mathrm{P} 40$ as the photoperiod switch day to (1) allow the retina to mature and (2) distinguish between developmental and transient effects. The mouse housing environments' light intensity was $100 \pm 15$ lux, provided by fluorescent bulbs. Food and water were provided ad libitum.

Electroretinogram. The electroretinogram (ERG) was used to assess global retinal cell function using the LKC Technologies UTAS visual electrodiagnostic test system as previously reported (Jackson et al., 2012). Here, we investigated the photopic (light-adapted) and scotopic (darkadapted) ERG recordings in the photoperiod groups, as previously described (Cameron et al., 2008a,b) with minor modifications. Mice were dark adapted overnight ( $\sim 15$ to $18 \mathrm{~h}$ ), then under dim red light (Kodak GBX-2 Safelight) they were anesthetized with an intraperitoneal injection of ketamine $(70 \mathrm{mg} / \mathrm{kg})$ and xylazine $(7 \mathrm{mg} / \mathrm{kg})$ and their pupils dilated with $1 \%$ tropicamide. For ERG analysis, Long, Short, and Equinox mice were tested at the middle of the light phase $(8,4$, and $6 \mathrm{~h}$ after subjective light onset; Fig. 1, gray arrows). Eyes were kept moist with $10 \%$ methylcellulose eye drops and core body temperature was maintained at $\sim 37.0^{\circ} \mathrm{C}$ using a thermostatically controlled heating pad regulated by a rectal temperature feedback probe (Model TC-1000 Temperature Controller; CWE). Needle electrodes were placed in the middle of the forehead and base of the tail, which served as reference and ground leads, respectively. A gold contact lens electrode was used for recording ERG responses (LKC Technologies; Order \#N30).

Scotopic ERG responses were differentially amplified and filtered (bandwidth: 0.3-500 Hz), with responses digitized at $1024 \mathrm{~Hz}$. The recording epoch was $250 \mathrm{~ms}$, with a $20 \mathrm{~ms}$ prestimulation baseline. A total of eight stimulus intensities, ranging from -3.60 to $1.37 \log \mathrm{cd}^{*} \mathrm{~s} / \mathrm{m}^{2}$, were used under dark-adapted conditions. Flash duration was $20 \mu \mathrm{s}$ and performed in order of increasing intensity. As flash intensity increased, retinal dark adaptation was maintained by increasing the interstimulus interval from 30 to $180 \mathrm{~s}$.

For photopic ERGs, mice were presented with a steady rod photoreceptor-saturating background-adapting field $\left(40 \mathrm{~cd} / \mathrm{m}^{2}\right)$ inside the UTAS BigShot ganzfeld. Simultaneously, $0.90 \mathrm{log} \mathrm{cd}^{*} \mathrm{~s} / \mathrm{m}^{2}$ bright light flashes were presented at $0.75 \mathrm{~Hz}$ during a $20.8 \mathrm{~min}$ period of light adaptation. Data were collected and averaged in $2.6 \mathrm{~min}$ bins, totaling eight bins ( 6 bins for photopic circadian experiment). Data collection occurred at similar time periods as the scotopic tests; however, additional photopic ERGs were recorded during the middle of the animals' dark phase. All other test parameters were similar to the scotopic ERG.

For the photopic ERG rescue experiment, intraperitoneal injections of $1 \mathrm{mg} / \mathrm{kg}$ SKF38393 (Sigma-Aldrich) and $1 \mathrm{mg} / \mathrm{kg}$ PD168077 (Tocris Bioscience) were administered to S:S mice $1 \mathrm{~h}$ before testing. Mice were injected under dim red light and returned to dark box until testing. Previous studies show that the $1 \mathrm{mg} / \mathrm{kg}$ drug concentration used fully restores a dopamine-depleted retina's function at the electrophysiological, behavioral, and pharmacological levels (Jackson et al., 2011, 2012). The S:S injected mice were compared with uninjected S:S mice.

The a-wave and b-wave amplitudes and implicit times of the respective ERG tests were analyzed off-line. ERG waveforms were filtered (low-pass $60 \mathrm{~Hz}$ ) to remove the influence of oscillatory potentials. For scotopic ERGs, the amplitude of the a-wave was measured from the prestimulus baseline (corresponding to flash onset) to the trough of the first negative deflection and the b-wave, from the trough of the a-wave to peak of the b-wave amplitude. For photopic ERG, only the b-wave was measurable, and was determined from the onset of the flash to the peak of the wave.
The implicit times of each ERG test were measured from flash onset to the peak of each wave.

Visual psychophysical testing. Visual-behavioral performance was assessed using the optokinetic head-tracking reflex, testing for spatial frequency threshold (acuity) and contrast detection (sensitivity) using the OptoMotry system (Cerebral Mechanics). Video analysis enabled an observer to track the reflexive head movements of mice in response to rotating sinusoidal-wave gradients projected by four interfacing Dell LCD monitors. Tracking was defined as smooth head movements tracked in the same direction and speed as the rotation of the sinusoidalwave gradient. Spatial frequency threshold was measured using a staircase method with a random and separate display of spatial frequencies and rotation direction, respectively, of the sinusoidal gradient. This procedure automatically increased the spatial frequency of the sinusoidal-wave gradient until the observer could no longer determine head-tracking movements.

Contrast sensitivity detection was measured similarly to spatial frequency threshold; however, the sinusoidal contrast gradients were systematically reduced from $100 \%$ contrast, at each spatial frequency, until no reflexive head movements were observed. The last contrast level where the observer noticed tracking was deemed the animals contrast sensitivity threshold. As described by Prusky et al. (2004), we measured contrast sensitivity threshold at six spatial frequencies $(0.031,0.064$, $0.092,0.103,0.192$, and 0.272 cycles/degree). The contrast sensitivity was calculated using a Michelson contrast from the screen's luminance (maximum - minimum $) /($ maximum + minimum $)$ as previously described (Prusky et al., 2004, 2006).

For each visual test Long, Short, and Equinox mice were tested at the middle of the light phase on their light cycle - 8, 4, or $6 \mathrm{~h}$ after light onset, respectively, under typical room lighting.

HPLC determination of biogenic amine concentration. Retinas from all groups were removed from the whole mouse eye and separated from the retinal pigment epithelium. Retinas were collected under either dark or light conditions at the middle of the subjective light phase, approximately $8 \mathrm{~h}$ or $4 \mathrm{~h}$ after light onset. Under dark conditions, mouse retinas were dissected in the presence of filtered dim-red light (Kodak GBX-2 Safelight). Under light conditions, retinas were dissected in the presence of room lighting, which is similar to the background light presented during the photopic ERG test. Immediately, both retinas from a single mouse, once dissected, were placed in a $1.5 \mathrm{ml}$ tube, frozen on dry ice, and stored at $-80^{\circ} \mathrm{C}$ until processed for HPLC analysis.

Retinas were homogenized, using a tissue dismembrator, in 100-750 $\mu \mathrm{l}$ of $0.1 \mathrm{M} \mathrm{TCA}$, which contains $10^{-2} \mathrm{M}$ sodium acetate, $10^{-4} \mathrm{M}$ EDTA, $5 \mathrm{ng} / \mathrm{ml}$ isoproterenol (as internal standard), and 10.5\% methanol, $\mathrm{pH}$ 3.8. Samples were spun in a microcentrifuge at $10,000 \mathrm{~g}$ for $20 \mathrm{~min}$. The supernatant was removed and stored at $-80^{\circ} \mathrm{C}$ (Cransac et al., 1996). The pellet was saved for protein analysis. Supernatant was thawed and spun for $20 \mathrm{~min}$ and samples of the supernatant were then analyzed for biogenic monoamines.

Retinal biogenic amines were determined by a specific HPLC assay using an Antec Decade II (oxidation: 0.4; 3 mm GC WE, HyREF) electrochemical detector operated at $33^{\circ} \mathrm{C}$. Twenty microliter samples of the supernatant were injected using a Water 2707 autosampler onto a Phenomenex Kinetex $(2.6 \mathrm{u}, 100 \mathrm{~A})$ C18 HPLC column $(100 \times 4.60 \mathrm{~mm})$. Biogenic amines were eluted with a mobile phase consisting of $89.5 \% 0.1$ $\mathrm{M}$ TCA, $10^{-2} \mathrm{M}$ sodium acetate, $10^{-4} \mathrm{M}$ EDTA, and $10.5 \%$ methanol, $\mathrm{pH}$ 3.8. Solvent was delivered at $0.6 \mathrm{ml} / \mathrm{min}$ using a Waters 515 HPLC pump. Using this HPLC solvent the following biogenic amines elute in the following order: dopamine, dihydroxyphenylacetic acid (DOPAC), homovanillic acid (HVA; Lindsey et al., 1998). HPLC control and data acquisition are managed by Empower software. For this investigation retinal biogenic amine analysis are represented as $\mathrm{ng} / \mathrm{mg}$ protein.

Total retinal protein concentration was determined using BCA Protein Assay Kit purchase (Pierce Chemical Company). The frozen pellets were allowed to thaw and reconstituted in a volume of $0.5 \mathrm{~N} \mathrm{HCl}$ that equals that previously used for tissue homogenization; $100 \mu \mathrm{l}$ of this solution was combined with $2 \mathrm{ml}$ of color reagent and allowed to develop for $2 \mathrm{~h}$. A bovine serum albumin standard curve was run at the same time 
spanning the concentration range of $20-2000 \mu \mathrm{g} / \mathrm{ml}$. Absorbance of standards and samples were measured at $562 \mathrm{~nm}$.

Retinal RNA extraction and quantitative RT-PCR. L:L, S:S, and Equinox mouse retinas were removed from whole eye, then frozen in a $1.5 \mathrm{ml}$ tube on dry ice. Samples were collected at six time points under the following light conditions: (1) L:L light phase-Zeitgeber Time (ZT) 2, 6, 10, and 14 and dark phase-ZT 18 and 22; (2) S:S light phase-ZT 2 and 6 and dark phase-ZT 10, 14, 18, and 22; (3) Equinox light phase-ZT 2, 6, and 10 and dark phase-ZT 14, 18, and 22. Samples were collected during the animal's dark phase under filtered dim-red light (Kodak GBX-2 Safelight) and stored at $-80^{\circ} \mathrm{C}$ until RNA extraction. Total RNA was extracted using a Qiagen RNeasy mini kit (catalog \#74104), measured by a NanoDrop system (Thermo Scientific), and reverse-transcribed ( $\sim 500$ ng) into cDNA using the QuantiTect Reverse Transcription Kit (Qiagen; category \#205311). Total cDNA was also measured to use for normalization. Quantitative RT-PCR reactions were performed in $25 \mu$ l total volume with $2 \mu \mathrm{l}$ cDNA, $12.5 \mu \mathrm{l}$ of SsoAdvanced SYBR Green Supermix (Bio-Rad), $8.5 \mu \mathrm{l}$ sterile water, and $1 \mu \mathrm{l}$ of $300 \mathrm{~nm}$ intron-spanning gene-specific forward and reverse primers in a Bio-Rad CFX96 RealTime System. Quantification of transcript levels was performed by comparing the threshold cycle for amplification of the unknown to those of six concentrations of standard cDNAs for each respective transcript, then normalizing the standard-calculated amount to the total concentration of cDNA in each sample. Each sample was assayed in duplicate.

Immunohistochemistry. L:L and S:S mice were assessed for changes in tyrosine hydroxylase positive $\left(\mathrm{TH}^{+}\right)$cell numbers. During the middle of the animals' light phase, L:L and S:S mice were killed by cervical dislocation and their eyes were removed and hemisected to remove cornea and lens; the eyecups were fixed in $4 \%$ formaldehyde for $1 \mathrm{~h}$. The retinas were then removed, washed with $1 \times$ PBS, and protected by sucrose gradients ( $10 \%$ for $30 \mathrm{~min}, 20 \%$ for $2 \mathrm{~h}$, and $30 \%$ overnight). After freezing on dry ice and thawing twice, retinal whole mounts were washed in $1 \times \mathrm{PBS}$, then blocked for $2 \mathrm{~h}$ with $5 \%$ goat serum, $0.1 \%$ Triton X-100 in $1 \times$ PBS, and incubated with primary anti-tyrosine hydroxylase antibody (Millipore Bioscience Research Reagents; $\mathrm{AB} 152)$ at $4^{\circ} \mathrm{C}$ overnight (1:500 anti$\mathrm{TH}, 3 \%$ goat serum, and $0.1 \%$ Triton $\mathrm{X}-100$ in $1 \times \mathrm{PBS})$. After rinsing with $1 \times$ PBS, fluorescent secondary antibody was applied (1:500 Alexa Fluor $488,1 \%$ goat serum, and $0.1 \%$ Triton $\mathrm{X}-100$ in $1 \times \mathrm{PBS}$ ), followed by a final series of PBS washes. Whole mounts were covered in Vectashield (Vector Laboratories) and viewed by confocal microscope. Images were processed via ImageJ (National Institutes of Health, Bethesda, MD) and MetaMorph (Molecular Devices).

Statistical analysis. Two-tailed $t$ test and one- and two-way ANOVAs were used where applicable and reported. Post hoc Student-NewmanKuels and Dunn's methods were used to identify sample means that are significantly different from each other after ANOVAs. Significance levels were set at $p<0.05$ and graphs are represented as means \pm SEM or SD where applicable and reported.

\section{Results}

To test the effect of seasonal circadian light cycles on retinal function, C57 mice were raised on modified photoperiods from E0 to P71 (Fig. 1), which consisted of Long (16 h light:8 h darkness) and Short ( $8 \mathrm{~h}$ light:16 h darkness) light cycles. In addition, to test for reversibility or persistence of developmental photoperiod effects, at P40-P50 some mice were switched to the opposing photoperiod for at least 3 weeks, followed by testing between P61 and P71. Finally, for comparison, cohorts of mice raised on the standard 12:12 Equinox photoperiod were considered controls in the study.

\section{Developmental photoperiod imprints retinal function}

We used the ERG to examine impacts of photoperiod on retinal function. Figure 2 shows photopic (Fig. 2A) and scotopic (Fig. $2 B, C)$ ERG responses following development and maintenance on Long, Short, and Equinox photoperiods (left column), or developmental exposure followed by photoperiod switch (right col-

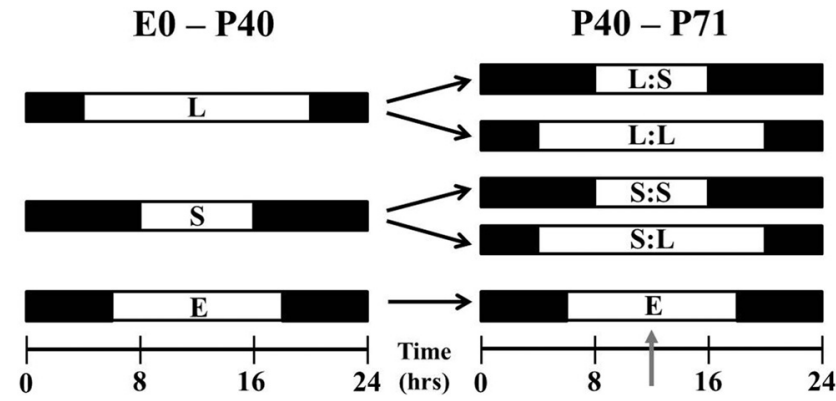

Figure 1. Photoperiod paradigm. Experimental photoperiod for mice began at E0 with either long (L) or short (S) light exposure. Between P40 and P50, groups either remained in the initial photoperiod or entered the opposing photoperiod for $\sim 3$ weeks. Other mice were ex posed to an Equinox ( $\mathrm{E} ; 12: 12 \mathrm{~h}$ ) light/dark cycle for comparison. Gray arrow signifies midday test time point.

A

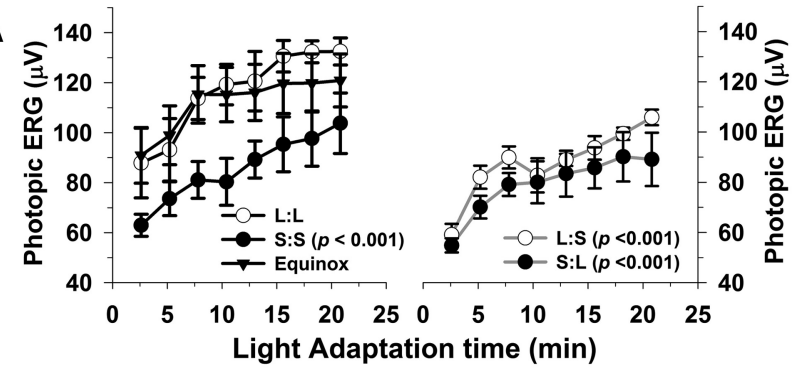

B
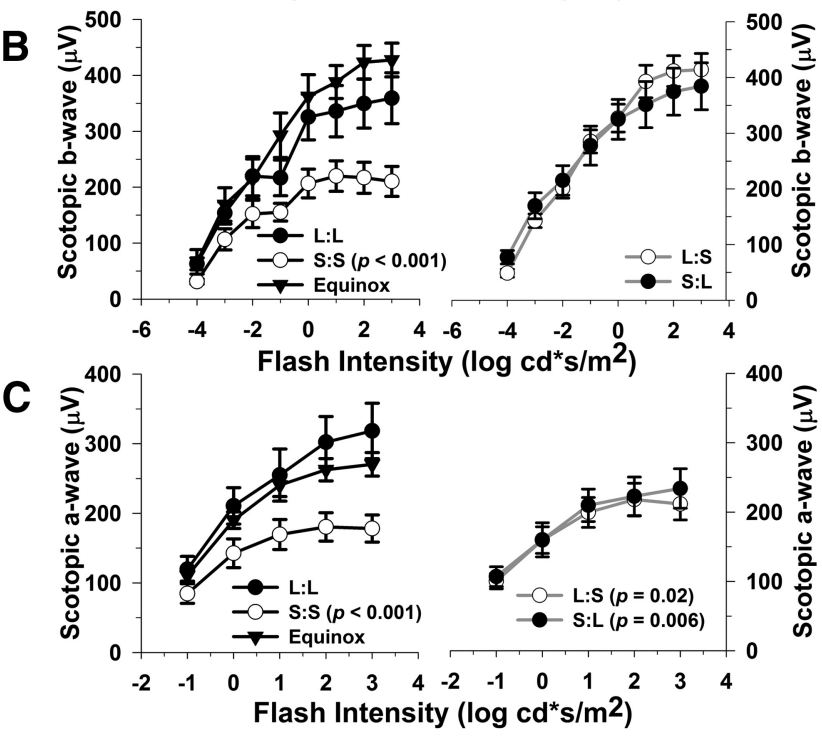

Figure 2. Photoperiod affects light- and dark-adapted retinal function. $\boldsymbol{A}$, Light-adapted (photopic) b-wave amplitudes are significantly lower in mice exposed to S:S, L:S, and S:L photoperiods as compared with L:L ( $p<0.001$, all groups). $B$, Dark-adapted (scotopic) b-wave amplitudes are significantly reduced in the $S: S$ mice compared with the L:L group ( $p<0.001)$. In contrast, the L:S and S:L groups do not differ from L:L; however, they are significantly higher in amplitude compared with S:S mice ( $p<0.05$, both comparisons). C, Dark-adapted (scotopic) a-wave amplitudes are lower in the S:S, L:S, and S:L groups in relation to L:L mice ( $p=<$ $0.001,0.022,0.006$, respectively). Also, the L:S and S:L groups significantly differ in amplitude compared with S:S mice ( $p=0.018$ and 0.024 , respectively). All data points represent means $\pm \mathrm{SEM} ; n=6-10$.

umn). Development in the Short photoperiod led to significant deficits in photopic responses where, on average, the $\mathrm{S}: \mathrm{S}$ group (8:16 photoperiod from E0 to P61-P71) showed an averaged $26 \%$ decrease in photopic b-wave amplitudes as compared with the L:L (16:8 photoperiod from E0 to P61-P71) and Equinox groups (12:12 photoperiod from E0 to P61-P71), while L:L and Equinox 


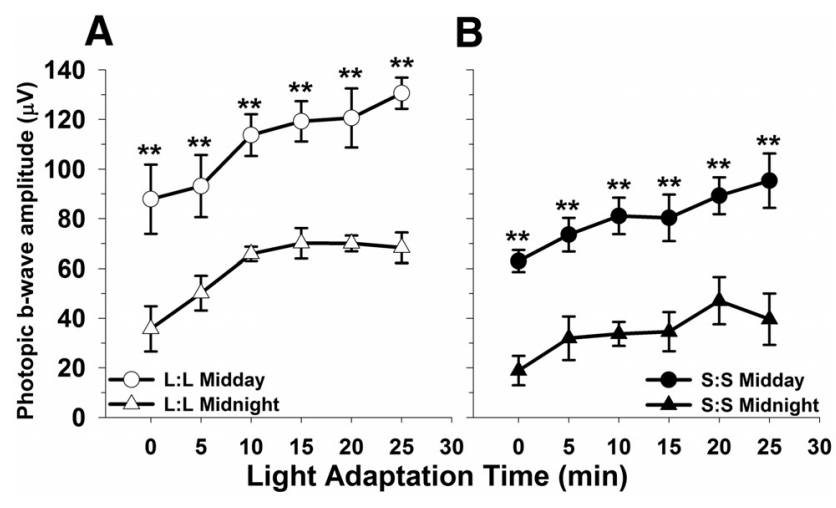

Figure 3. Photoperiod does not affect photopic ERG rhythm phenotype, only the amplitude differs between groups. $\boldsymbol{A}, \boldsymbol{B}, \mathrm{L}: \mathrm{L}$ and $\mathrm{S}: S$ animals display rhythmic responses to the photopic test ${ }^{* *} p<0.001$, both groups: day vs night); however, the amplitude in the $S: S$ group is significantly lower as compared with the $L: L$ at the corresponding test time point ( $L: L$ v S:S midday, $p<0.001$; L:L vs S:S midnight, $p<0.001$ ). All data points represent means $\pm \mathrm{SEM} ; n=6$

were indistinguishable (Fig. 2A, left column; S:S vs L:L and Equinox, $p<0.001$ ). Switching from Short to Long photoperiods at P40-P50 until testing at P61-P71 did not restore the amplitudes of the Short photopic b-wave; in fact, a small but significant $15 \%$ average amplitude decrease was observed (S:L group; Fig. $2 A$, right column; S:S vs S:L, $p<0.017$ ), indicating that the developmental effect of Short photoperiods persists even following $\sim 3$ weeks of Long photoperiod exposure. In addition, switching the Long group to the short photoperiod decreased the amplitude of the photopic ERG to levels similar to the S:S group (Fig. $2 A$, left column, L:S; $p<0.001$, as compared with $\mathrm{L}: \mathrm{L})$.

Because the photopic ERG b-wave response is expressed with a circadian rhythm (Storch et al., 2007; Cameron et al., 2008a; Jackson et al., 2012 ), we tested whether the decrement in photopic ERG amplitude we had observed at midday was also present at midnight. Indeed photopic ERG amplitudes from both L:L and $\mathrm{S}: S$ groups displayed day/night differences, with reduced amplitudes at night (Fig. $3 A, B$, left column, L:L ${ }^{* *} p<0.001$; right column, $\mathrm{S}: \mathrm{S}^{\star *} p<0.001$, day vs night). Moreover, the photopic response in $\mathrm{S}: \mathrm{S}$ mice was significantly reduced at both midday and midnight time points compared with L:L (Fig. $3 A, B ; p<$ 0.001 for all comparisons). Photopic a-waves could not be reliably measured in our system.

The scotopic b-wave was also reduced in S:S reared mice compared with the L:L and Equinox groups (Fig. 2B, left column; 36\% vs $L: L, p<0.001)$. In contrast, the scotopic b-wave response was restored by switching mice from the short to long photoperiod $(\mathrm{S}: \mathrm{L})$, which indicates that this activity responds to the longer light cycle. In addition, the amplitudes of the scotopic b-wave were maintained at high levels in the L:S group demonstrating a sustained ERG phenotype (Fig. $2 B$, right column; L:S vs S:S, $p<$ 0.001; S:L vs S:S, $p<0.001)$.

The S:S, L:S, and S:L groups demonstrated an average 36\%, $25 \%$, and $21 \%$ decrease, respectively, in scotopic a-wave amplitudes in relation to the L:L and Equinox groups (Fig. $2 C ; p \leq$ $0.001,0.022$, and 0.006, respectively). Moreover, L:S and S:L groups were $\sim 15 \%$ higher than the S:S group (Fig. $2 C ; p=0.018$ and 0.024 , respectively). L:S and S:L group a-wave amplitudes were partially reduced and restored, respectively, indicating an intermediate phenotype.

Psychophysical-visual tests using optokinetic tracking were performed to assess the impact of seasonal photoperiods on vi-

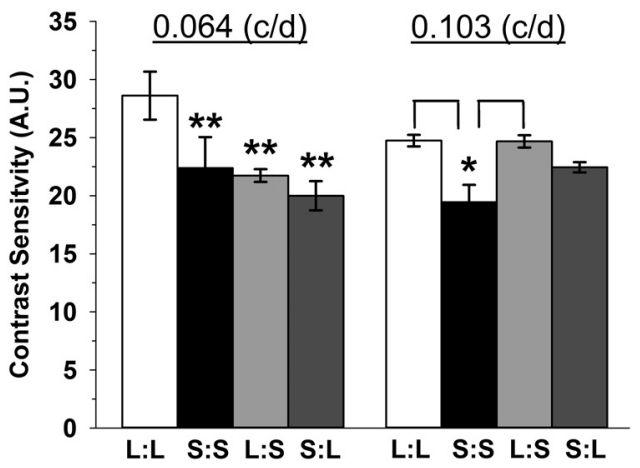

Figure 4. Contrast sensitivity detection is impacted by perinatal photoperiod exposure. Contrast sensitivity is lower in S:S, L:S, and S:L groups at 0.064 cycles per degree (c/d) compared with L:L mice $\left({ }^{* *} p<001\right)$. Also, at $0.103 \mathrm{c} / \mathrm{d}$, contrast sensitivity is significantly reduced in S:S mice compared with $\mathrm{L}: \mathrm{L}$ and $\mathrm{L}: S$ exposed mice $\left({ }^{*} p=0.004\right)$. All data represent means $\pm \mathrm{SEM}$; $n=4-6$ mice. A.U., arbitrary units.

sion. Contrast sensitivity in S:S, L:S, and S:L mice was significantly decreased compared with the L:L photoperiod group (Fig. $4,0.064$ cycles/degree; ${ }^{\star *} p=0.001$ ), and the S:S mice also showed a significant deficit relative to the L:L and L:S groups at 0.103 cycles/degree (Fig. $4 ;{ }^{\star} p<0.05$ ). Spatial frequency threshold (acuity) was also measured across all photoperiod groups; however, no differences were found (data not shown).

\section{Dopamine content is influenced by photoperiod}

The deficits in retinal function in the Short photoperiod micereduced photopic b-wave amplitude and contrast sensitivityare similar to those produced by genetic depletion of dopamine in the mouse retina (Jackson et al., 2012). Therefore, to determine whether the retinal dopaminergic system is influenced by seasonal photoperiods, we assayed for changes in dopamine, DOPAC, and HVA levels. The S:S, L:S, and S:L groups displayed approximately $20 \%, 28 \%$, and $50 \%$ reductions in retinal dopamine levels, respectively, compared with the L:L group (Fig. $5 B$; $\left.{ }^{* *} p<0.001\right)$. S:S and L:S groups show $18 \%$ and $50 \%$ lower amounts of retinal DOPAC in relation to L:L (Fig. $5 C$; ${ }^{* *} p<$ $0.05)$; in contrast, the $\mathrm{S}: \mathrm{L}$ group did not differ. It is noted that there is a substantial increase in DOPAC in the S:L group when compared with the S:S and L:S groups (Fig. $5 \mathrm{C} ;{ }^{\Delta} p<0.05$ ). HVA levels were $25 \%$ lower in the L:S exposed mice (Fig. $5 D ;{ }^{*} p<$ 0.05 ), while all other groups did not significantly differ compared with L:L. The DOPAC/dopamine (DA) ratio was approximately doubled in the S:L group as compared with the L:S mice $(p<$ $0.05)$; all other groups did not differ. Also, HVA/DA ratios among the photoperiod groups did not differ (data not shown).

The observed decrease in dopamine content in short photoperiod retinas could be due to a decrease in dopamine synthesis or a decrease in the number of retinal dopaminergic amacrine/ interplexiform cells. To address these possibilities, we determined retinal dopaminergic cell density in the L:L and S:S groups, using immunohistochemistry for tyrosine hydroxylase, the ratelimiting enzyme in dopamine synthesis. These groups did not differ in cell density (L:L: $36.4 \pm 4.1$ cells $/ \mathrm{mm}^{2}$; S:S: $38.02 \pm 3.0$ cells $/ \mathrm{mm}^{2}$ ) for cells that positively reacted to tyrosine hydroxylase antibody detection. These cell densities are similar to mice that were reared in Equinox conditions ( 34 cells $/ \mathrm{mm}^{2}$; Zhang et al., 2004).

\section{Restoration of dopamine signaling rescues retinal function}

To test if restoring dopaminergic signaling rescues the photopic ERG deficit in the Short photoperiod group, we injected S:S mice 

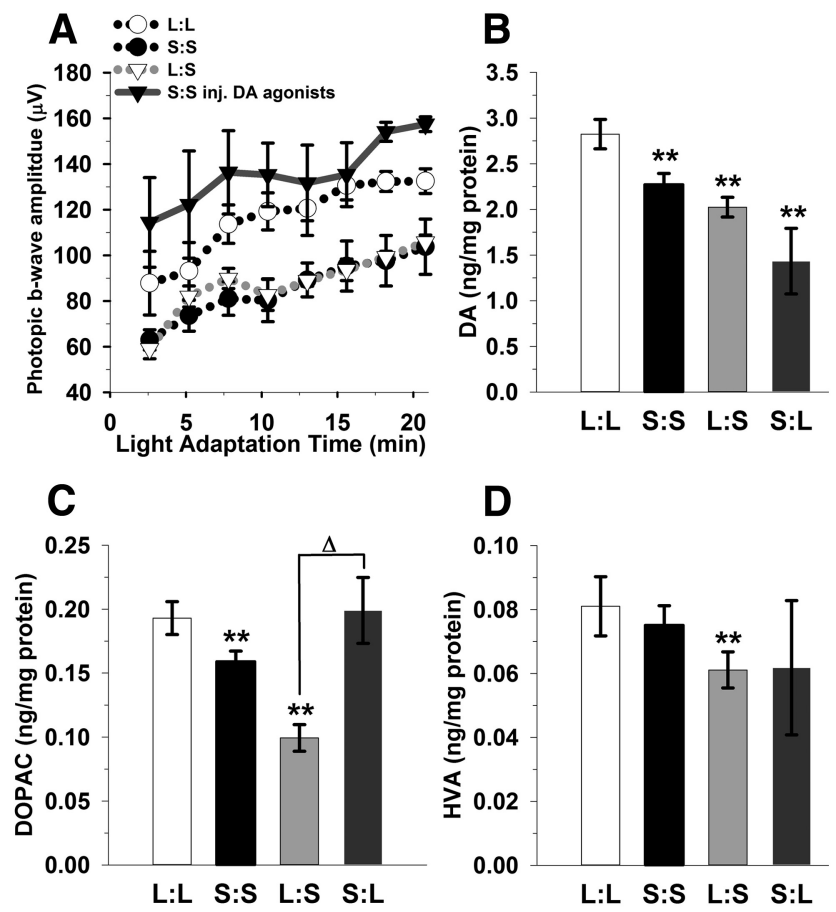

Figure 5. Stimulating dopaminergic signaling rescues the photopic ERG. A, Injection of SKF38393 and PD168077 (1 mg/kg, dopamine D1 and D4 receptor-selective agonists, respectively) significantly increases photopic ERG b-wave amplitudes in the S:S group (solid gray line with black triangles) compared with the untreated group (black dotted line; $p=0.018) . B$, Retinal dopamine is reduced in $S: S, L: S$, and $S: L$ groups compared with L:L mice $\left.{ }^{* *} p<0.05\right)$. C, Retinal DOPAC concentrations are lower in S:S Sand L:S mice in relation to L:Lmice $\left.{ }^{* *} p<0.05\right)$; however, S:L does not significantly differ. $D$, In contrast, only the L:S mice display a significant reduction in HVA compared with L:L mice ${ }^{* *} p<$ 0.05). All data represent means $\pm \mathrm{SEM} ; n=6-8$ mice.

with dopamine D1 and D4 receptor agonists ( $1 \mathrm{mg} / \mathrm{kg}$ per drug) $1 \mathrm{~h}$ before testing their photopic ERG. Dopamine agonist treatment indeed reversed the short photoperiod-induced deficit, increasing the light-adapted b-wave amplitudes by an average of $37 \%$ compared with the untreated S:S group (Fig. $5 A ; p=0.018$ ). Previous studies show that the scotopic a-wave and b-wave ERG light response is not affected by retinal dopamine depletion; therefore, this test was not performed (Jackson et al., 2012).

Photoperiod influences dopamine synthetic gene expression Given the reduction in dopamine content in S:S retinae, but lack of change in dopamine cell number, we assayed for changes in the expression of tyrosine hydroxylase (Th), the rate-limiting enzyme for dopamine synthesis. Th mRNA levels were assayed at $4 \mathrm{~h}$ intervals over a $24 \mathrm{~h}$ period to determine both the overall and temporal expression patterns. Th mRNA levels were, on average, $\sim 60 \%$ lower in retinas from $S: S$ photoperiod mice, compared with L:L or Equinox mice (Fig. 6; $p<0.001$, both comparisons). In addition, the temporal expression pattern between all groups appeared to differ; even so, each showed a similar peak in Th expression following the light/dark transition (Fig. 6A).

One of the key regulators of Th gene expression that links it to neural activity is the immediate early gene transcription factor Early Growth Response factor-1 (Egr-1). We tested the overall and temporal expression pattern of Egr-1 mRNA levels in the same retinal samples as used to measure Th expression, and found that they were statistically lower in $S: S$ and Equinox groups as compared with L:L mice (Fig. $6 B ; p<0.05$, all comparisons), with no observed difference between $S: S$ and Equinox. The peak in expression of Egr-1 following the light/dark transition was
A

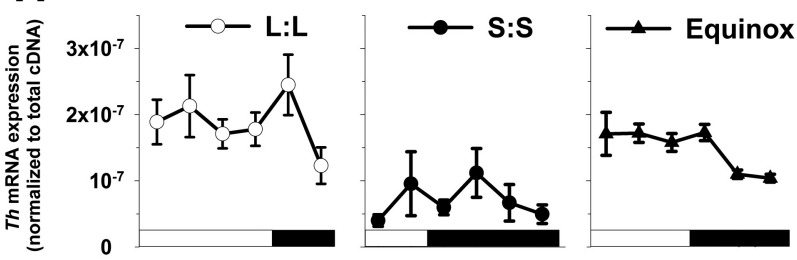

B
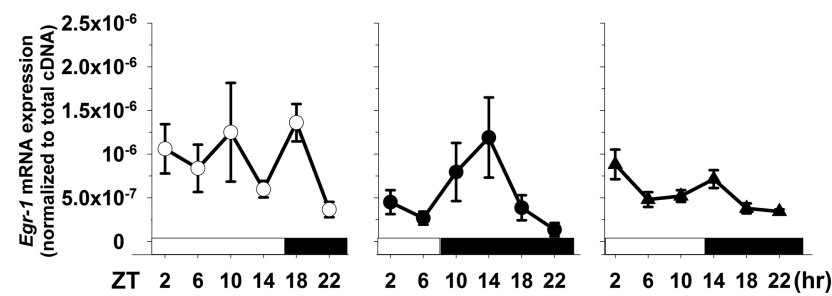

Figure 6. Tyrosine hydroxylase and Egr- $1 \mathrm{mRNA}$ expression levels are influenced by perinatal photoperiod. $\boldsymbol{A}$, Th retinal mRNA levels, assayed over $24 \mathrm{~h}$, differ among all photoperiods ( $p<0.01$ ); even so, mice exposed to the S:S photoperiod display the lowest $T h$ mRNA levels compared with L:L and Equinox reared mice $(p<0.001)$. $\boldsymbol{B}$, Egr-1 mRNA expression patterns substantially differ between the three groups $(p=0.015)$. S:S and Equinox levels are significantly lower compared with the L:L group $(p<0.01$ and 0.001 , respectively). Transcript expression peaks after the light to dark transition in each group. All data points represent means $\pm \mathrm{SEM} ; n=6$ mice per group per time point.

common among all photoperiods, and was similar to how Th reacts to the change in light environment. Thus, we provide evidence that developmental photoperiod significantly impacts retinal dopamine and the molecular machinery known to be active in its production.

\section{Discussion}

Overall, we observed that circadian light cycles experienced during retinal development/maturation have enduring influence on retinal physiology and a marked impact on vision in adulthood. Altered retinal dopamine signaling is likely a key contributor to the functional deficits observed in this study.

\section{Photoperiod has enduring and transient effects on retinal function}

The retina adjusts its functional capacity to handle exponential changes in daily illumination, for example, the shift from nighttime to daytime vision. Retinal dopamine is a primary factor coordinating this functional transition from a rod- to conedominated state, which is observed in the light-adapted ERG response and closure of photoreceptor gap junction connectivity (Jackson et al., 2012; Li et al., 2013). Light drives retinal tyrosine hydroxylase activity and subsequently dopamine production (Iuvone et al., 1978a); acute light exposure of $15 \mathrm{~min}$ or $96 \mathrm{~h}$ results in increased activity of tyrosine hydroxylase and more active enzymes, respectively (Iuvone et al., 1978b). However, this activity amplification is readily reversed with $24 \mathrm{~h}$ of dark exposure. In contrast, the short photoperiod model limited light exposure to $8 \mathrm{~h}$ per day during development, which results in enduring changes in the retinal dopamine phenotype that are not reversed by weeks of $16 \mathrm{~h}$ daylight exposure. Therefore, the enduring deficits observed in light-adaptive vision in mice exposed to short light cycles are likely due to insufficient photoperiodic programming of the retinal dopaminergic system due to less daily light stimulation during development. It is plausible that the retinal dopamine decreases observed in adult mice switched from the long to short photoperiod are due to less proximal daily light 
drive, which could result in a similar functional phenotype. Also, untested retinal processes, such as a reduction in the lightadaptation kinetics, could play a role in the photopic response deficits.

Reduced levels of retinal dopamine and a possible dopamine D4 receptor expression alteration, as a result of photoperiod exposure, could explain why there are incremental differences among the spatial frequencies in the contrast sensitivity test. Dopamine controls contrast sensitivity through activation of the dopamine D4 receptor (Hwang et al., 2013). This receptor's expression in the retina is rhythmic and driven by light (Storch et al., 2007; Jackson et al., 2011); thus, it is possible that, in conjunction with lower retinal dopamine, the dopamine D4 receptor levels are altered by exposure to short daily light cycles. Mice are most sensitive in detecting difference in contrast at 0.064 cycles/ degree. The other frequencies (i.e., 0.103 cycles/degree) do not refine contrast at a similar level (Prusky et al., 2004); therefore, slight photoperiodic retinal dopaminergic modifications may not be resolved at the other spatial frequencies.

The observed reduction in scotopic a-wave and b-wave properties in short photoperiod mice is unlikely due to a change in dopamine signaling since (1) substantially reducing retinal dopamine does not impact the scotopic ERG light response and (2) rod photoreceptors, which mediate this response, do not express dopamine receptors (Jackson et al., 2012). Previous reported evidence does suggest that lighting conditions can affect photoreceptor synaptic ribbon numbers and morphology (Fuchs et al., 2013). Photoperiod input could alter ribbon synapse structure leading to the transient changes we observe in the scotopic b-wave of the Short to Long photoperiod group. Also, it is plausible that 3 weeks is insufficient to transition this system to a new light cycle, which could explain why we did not detect complete a-wave or b-wave amplitude photoperiod reversal.

Our developmental photoperiod exposures cover the entire time course of development and maturation of the retina. Within that interval there are a variety of time points that could serve as a critical period. Light, as early as E16, influences the development of the retina (Rao et al., 2013). In the mouse fetus, light stimulation of the melanopsin system is critical for normal retinal vascular development, which if perturbed, leads to increased vascular growth (Rao et al., 2013). This system is known to affect the retinal dopaminergic system. Rearing mice in complete darkness alters inner nuclear layer retinal synaptic organization and dopamine storage, demonstrated by changes in light-evoked retinal ganglion cell responses, ERG measured oscillatory potentials, and retinal ON-/OFF-pathways (Tian and Copenhagen, 2001; Vistamehr and Tian, 2004). Short-term light deprivation has no detectable effects on retinal function; however, light exposure influences retinal physiology during a critical period, between P22 and P40 in mice (Tian and Copenhagen, 2001). Dopamine and melanopsin phototransduction influences the generation of retinal waves (P4-P7), which are required for visual development (Renna et al., 2011, Kirkby and Feller, 2013). Altering the duration of light input during retinal development could significantly impact how the retina refines inner retinal circuits for contrast detection and vision, thereby, shaping retinal function along several dimensions.

The developmental light cycles in our experiments varied in three ways: the timing of daily light/dark transitions for circadian entrainment, the duration of light each day, and the total number of daily photons. These parameters mimic the seasonal changes in light cycles as experienced in the natural environment, which was our goal, but a limitation of our study is that we cannot strictly ascribe the effects observed to any one parameter of the three that were varied.

\section{Photoperiod impacts monoamine content}

Light causes a surge in dopamine release that acts via volume transmission to reconfigure the retina signaling capacity for daytime vision (Witkovsky, 2004). Here, mice exposed to the short photoperiod, either developmentally, or as adults, display significantly lower dopamine content than those reared and maintained on long photoperiods. However, uniquely among the groups, mice moved from a short to long photoperiod also show an increase in DOPAC and HVA, which indicates higher levels of dopamine metabolism. It is plausible that increased dopamine use and metabolism could contribute to the low retinal dopamine levels observed in this group. Previous studies show that the development of the retinal dopaminergic system requires stimulation from light-sensitive retinal cells (Iuvone et al., 1978a), and rearing mice in constant darkness results in both lower retinal dopamine and tyrosine hydroxylase expression (Melamed et al., 1986; Shelke et al., 1997). Here, we show that reduced light input from short photoperiods also reduces retinal dopamine and tyrosine hydroxylase mRNA ( $\sim 60 \%)$, suggesting that retinal light stimulation duration into dopaminergic amacrine cells plays an integral role in regulating this system during development and in the adult retina. Further studies need to be conducted to determine whether this molecular change has a developmental critical period, or can be evoked acutely.

In addition to decreased Th expression, the mice maintained on short photoperiods also display decreased retinal transcript levels of Egr-1. Egr-1, present in multiple retinal cell types, is known to drive Th expression in PC12 cells and is an active transcription factor that mediates diverse cellular systems (Papanikolaou and Sabban, 2000). Its semi-ubiquitous presence could explain why its expression differs among the photoperiod groups compared with $T h$. Further investigation is required to determine Egr-1's specific role within the retinal dopaminergic system in response to seasonal light cycles.

Light input has long-term effects on dopaminergic neurons in other brain areas as well. Six weeks of constant darkness increases apoptotic markers in the nuclei of ventral tegmental dopamine neurons. Furthermore, exposing rats to short and long circadian light cycles results in loss of dopamine expression and increase in somatostatin hypothalamic neurons (Gonzalez and Aston-Jones, 2008; Dulcis et al., 2013). Our results, in conjunction with these previous findings, show that circadian light input can regulate the activity and neurotransmitter expression in monoamine neurons in a number of neural centers, beginning with the retina.

Mice proficient in melatonin exhibit rhythmic dopamine levels; however, in our study, C57 mice were used and do not produce biologically relevant levels of melatonin, eliminating this rhythmic pattern (Doyle et al., 2002). Therefore, the observed decrease in retinal dopamine expression is not influenced by any potential changes in melatonin driven by seasonal light cycles.

\section{Photoperiodic programming of retinal physiology and seasonal affective disorder}

Disruption of retinal signaling is implicated in the pathophysiology of certain subtypes of clinical depression (Oren, 1991; Lam et al., 1992). For example, Seasonal Affective Disorder (SAD) affects a portion of the human population during winter months when photoperiods are shorter. These patients display irregularities in photopic and scotopic luminance responses, plus deficits in contrast sensitivity (Terman and Terman, 1999; Szabó et al., 2004; 
Wesner and Tan, 2006; Lavoie et al., 2009), essentially similar to those we observed in mice exposed to short light cycles. Recent studies show that SAD patients have lower retinal sensitivity as measured by ERG, which correlates with day length and can be readily treated with light therapy (Szabó et al., 2004; Gagné et al., 2007).

This study presents mechanistic evidence that retinal light responses, visual contrast sensitivity, and retinal dopamine are persistently decreased in mice by perinatal exposure to short light cycles. Interestingly, some seasonal human birth cohorts have increased risk of SAD (Foster and Roenneberg, 2008), suggesting the possibility that mechanisms similar to those we have described in mice may operate in humans.

\section{References}

Cameron MA, Barnard AR, Hut RA, Bonnefont X, van der Horst GT, Hankins MW, Lucas RJ (2008a) Electroretinography of wild-type and Cry mutant mice reveals circadian tuning of photopic and mesopic retinal responses. J Biol Rhythms 23:489-501. CrossRef Medline

Cameron MA, Barnard AR, Lucas RJ (2008b) The electroretinogram as a method for studying circadian rhythms in the mammalian retina. J Genet 87:459-466. CrossRef Medline

Ciarleglio CM, Axley JC, Strauss BR, Gamble KL, McMahon DG (2011) Perinatal photoperiod imprints the circadian clock. Nat Neurosci 14:2527. CrossRef Medline

Cransac H, Cottet-Emard JM, Pequignot JM, Peyrin L (1996) Monoamines (norepinephrine, dopamine, serotonin) in the rat medial vestibular nucleus: endogenous levels and turnover. J Neural Transm 103:391-401. CrossRef Medline

Doyle SE, Grace MS, McIvor W, Menaker M (2002) Circadian rhythms of dopamine in mouse retina: the role of melatonin. Vis Neurosci 19:593601. Medline

Dulcis D, Jamshidi P, Leutgeb S, Spitzer NC (2013) Neurotransmitter switching in the adult brain regulates behavior. Science 340:449-453. CrossRef Medline

Foster RG, Roenneberg T (2008) Human responses to the geophysical daily, annual and lunar cycles. Curr Biol 18:R784-R794. CrossRef Medline

Fuchs M, Sendelbeck A, Atorf J, Kremers J, Brandstätter JH (2013) Strain differences in illumination-dependent structural changes at mouse photoreceptor ribbon synapses. J Comp Neurol 521:69-78. CrossRef Medline

Gagné AM, Gagné P, Hebert M (2007) Impact of light therapy on rod and cone functions in healthy subjects. Psychiatry Res 151:259-263. CrossRef Medline

Goldman BD (2003) Pattern of melatonin secretion mediates transfer of photoperiod information from mother to fetus in mammals. Science's STKE 2003:PE29. Medline

Gonzalez MM, Aston-Jones G (2008) Light deprivation damages monoamine neurons and produces a depressive behavioral phenotype in rats. Proc Natl Acad Sci U S A 105:4898-4903. CrossRef Medline

Hubel DH, Wiesel TN (1962) Receptive fields, binocular interaction and functional architecture in the cat's visual cortex. J Physiol 160:106-154. Medline

Hwang CK, Chaurasia SS, Jackson CR, Chan GC, Storm DR, Iuvone PM (2013) Circadian rhythm of contrast sensitivity is regulated by a dopamine-neuronal PAS-domain protein 2-adenylyl cyclase 1 signaling pathway in retinal ganglion cells. J Neurosci 33:14989-14997. CrossRef Medline

Iuvone PM, Galli CL, Garrison-Gund CK, Neff NH (1978a) Light stimulates tyrosine hydroxylase activity and dopamine synthesis in retinal amacrine neurons. Science 202:901-902. CrossRef Medline

Iuvone PM, Galli CL, Neff NH (1978b) Retinal tyrosine hydroxylase: comparison of short-term and long-term stimulation by light. Mol Pharmacol 14:1212-1219. Medline

Jackson CR, Chaurasia SS, Hwang CK, Iuvone PM (2011) Dopamine $\mathrm{D}_{4}$ receptor activation controls circadian timing of the adenylyl cyclase 1/cAMP signaling system in mouse retina. Eur J Neurosci 34:57-64. CrossRef Medline
Jackson CR, Ruan GX, Aseem F, Abey J, Gamble K, Stanwood G, Palmiter RD, Iuvone PM, McMahon DG (2012) Retinal dopamine mediates multiple dimensions of light-adapted vision. J Neurosci 32:9359-9368. CrossRef Medline

Kirkby LA, Feller MB (2013) Intrinsically photosensitive ganglion cells contribute to plasticity in retinal wave circuits. Proc Natl Acad Sci U S A 29:12090-12095. CrossRef Medline

Lam RW, Beattie CW, Buchanan A, Mador JA (1992) Electroretinography in seasonal affective disorder. Psychiatry Res 43:55-63. CrossRef Medline

Lavoie MP, Lam RW, Bouchard G, Sasseville A, Charron MC, Gagné AM, Tremblay P, Filteau MJ, Hébert M (2009) Evidence of a biological effect of light therapy on the retina of patients with seasonal affective disorder. Biol Psychiatry 66:253-258. CrossRef Medline

Li H, Zhang Z, Blackburn MR, Wang SW, Ribelayga CP, O’Brien J (2013) Adenosine and dopamine receptors coregulate photoreceptor coupling via gap junction phosphorylation in mouse retina. J Neurosci 33:31353150. CrossRef Medline

Lindsey JW, Jung AE, Narayanan TK, Ritchie GD (1998) Acute effects of a bicyclophosphate neuroconvulsant on monoamine neurotransmitter and metabolite levels in the rat brain. J Toxicol Environ Health A 54:421-429. CrossRef Medline

Melamed E, Frucht Y, Vidauri J, Uzzan A, Rosenthal J (1986) Effect of postnatal light deprivation on the ontogenesis of dopamine neurons in rat retina. Brain Res 391:280-284. Medline

Oren DA (1991) Retinal melatonin and dopamine in seasonal affective disorder. J Neural Transm Gen Sect 83:85-95. CrossRef Medline

Papanikolaou NA, Sabban EL (2000) Ability of Egr1 to activate tyrosine hydroxylase transcription in PC12 cells. Cross talk with AP-1 factors. J Biol Chem 275:26683-26689. Medline

Prusky GT, Alam NM, Beekman S, Douglas RM (2004) Rapid quantification of adult and developing mouse spatial vision using a virtual optomotor system. Invest Ophthalmol Vis Sci 45:4611-4616. CrossRef Medline

Prusky GT, Alam NM, Douglas RM (2006) Enhancement of vision by monocular deprivation in adult mice. J Neurosci 26:11554-11561. CrossRef Medline

Rao S, Chun C, Fan J, Kofron JM, Yang MB, Hegde RS, Ferrara N, Copenhagen DR, Lang RA (2013) A direct and melanopsin-dependent fetal light response regulates mouse eye development. Nature 494:243-246. CrossRef Medline

Renna JM, Weng S, Berson DM (2011) Light acts through melanopsin to alter retinal waves and segregation of retinogeniculate afferents. Nat Neurosci 14:827-829. CrossRef Medline

Shelke RR, Lakshmana MK, Ramamohan Y, Raju TR (1997) Levels of dopamine and noradrenaline in the developing of retina-effect of light deprivation. Int J Dev Neurosci 15:139-143. CrossRef Medline

Storch KF, Paz C, Signorovitch J, Raviola E, Pawlyk B, Li T, Weitz CJ (2007) Intrinsic circadian clock of the mammalian retina: importance for retinal processing of visual information. Cell 130:730-741. CrossRef Medline

Szabó Z, Antal A, Tokaji Z, Kálmán J, Kéri S, Benedek G, Janka Z (2004) Light therapy increases visual contrast sensitivity in seasonal affective disorder. Psychiatry Res 126:15-21. CrossRef Medline

Terman JS, Terman M (1999) Photopic and scotopic light detection in patients with seasonal affective disorder and control subjects. Biol Psychiatry 46:1642-1648. CrossRef Medline

Tian N, Copenhagen DR (2001) Visual deprivation alters development of synaptic function in inner retina after eye opening. Neuron 32:439-449. CrossRef Medline

Vistamehr S, Tian N (2004) Light deprivation suppresses the light response of inner retina in both young and adult mouse. Vis Neurosci 21:23-37. CrossRef Medline

Wesner MF, Tan J (2006) Contrast sensitivity in seasonal and nonseasonal depression. J Affect Disord 95:19-28. CrossRef Medline

Witkovsky P (2004) Dopamine and retinal function. Doc Ophthalmol 108: 17-40. CrossRef Medline

Zhang DQ, Stone JF, Zhou T, Ohta H, McMahon DG (2004) Characterization of genetically labeled catecholamine neurons in the mouse retina. Neuroreport 15:1761-1765. CrossRef Medline 